\title{
College courses of clothing color the innovation of teaching methods and practice Song Ting ${ }^{1, a}$
}

1Jiangxi Institute of Fashion Technology, Jiangxi, Nanchang, 330201

${ }^{a}$ email

Keywords: Learn clothing color, Teaching methods, innovation

\begin{abstract}
This article fully understand the characteristics of clothing color design and we analyzed the advantages and disadvantages of using network multimedia teaching and traditional teaching methods in the clothing color design course. And we also explore how to efficiently use the advantages and disadvantages of network multimedia and traditional teaching methods in clothing color design to optimize teaching methods and improve the quality of the teaching of the course.
\end{abstract}

\section{Introduction}

Today, the widely using of modern multimedia network technology in classroom is an important means of teaching, more and more teachers and students have recognize it and love it. Network multimedia teaching and traditional teaching compared, showing a lot of advantages. But whether it is a network multimedia teaching or traditional teaching methods there are advantages and disadvantages, facing different courses and different teaching content, and how reasonable the network and multimedia tools combine traditional teaching methods and apply to clothing color design courses teaching, teaching each other to optimize and improve the quality of teaching is a need to be carefully explored.

\section{The Features of Clothing Color Design Courses}

"Clothing color design" is part of a costume design major scientific color theory, practical training to strengthen and improve the ability of the curriculum. As we all know, is a fashion-oriented clothing design industry, rapid changes described in this profession colors, styles, fabrics are called three elements. However, colors are arranged in the first one, the color with the "first" color takes away people's visual effects. To form and train students to visual intuition of this reaction, we must vigorously strengthen the implementation of practical aspects, as well as in teaching the visual stimuli as the dominant factor. This visual reaction can say that everyone born, but by training the subconscious aesthetic sense can dig deeper. The course is mainly played in the professional ability to improve the aesthetic and practical skills for the role. Therefore, clothing color design can be said to be easy to learn and difficult to master a course in fashion design profession.

\section{The Advantages of Network Multimedia Teaching in Clothing Color Design}

The Network Multimedia Teaching Has Illustrations and Large Visual Stimulation to Help Improve Gut Reaction. Use intuitive and image color images in network multimedia courseware can create a colorful and vivid teaching situation, clothing color design course is mainly formed with visual stimulation through a lot of color, these elements if monotonous language by teachers and students to imagine difficult to complete. For example, in the curriculum, teachers let students think of Violet reminiscent of what items and bring what emotions, even if rich language, students simply do not know why Violet how can they be trained Lenovo thinking. This time, the use of network multimedia teaching intuitive color into the big screen, after the students will soon be able to get into the visual stimulus learning environment, which can produce a great passion for learning and initiative. 
The Network Multimedia Teaching Can Keep up with Fashion Color Quickly. Clothing color design is ultimately for the color in the service of students through learning and grasp of color in fashion trends, and lay a solid foundation for the future to enter into social enterprises. However, knowledge of materials is limited, and it is required to set the content. Apparel is a stylish product, with some seasonal, textbooks through writing, printing have become obsolete, update their knowledge of the speed cannot meet the needs of fashion colors, this time using the network multimedia teaching teachers can publish the latest fashion, fashion color trends to teach to students, shortening the school to the corporate run-in period. For example, in "color in" the unit, you can put the latest compilation of fashion show according to the teaching content to the classroom, from multiple angles show clothing color match the aesthetic beauty and improve the dynamic performance under dynamic and static lectures, bang, active classroom atmosphere, and open up their horizons, learning to textbooks no knowledge by students like to improve learning initiative.

The Network Multimedia Teaching Can Stimulate Students' Interest in Learning. Network multimedia teaching plus adds fun on the traditional teaching of a single chalk blackboard, teaching the integrated use of sound, pictures, video, projectors and other media, so that the image of abstract color theory becomes concrete, so that both enhance learning is also proactive improves a strong sexual interest in learning. The use of multimedia teaching network to mobilize students to participate in various senses clothing color design courses, such as in "color hearing" This unit teaching, the color of which is driven by a sense of sympathy for the other four sense for color design. Traditional teaching us a certain kind of inspiring students to imagine the sound of memories brings color perception, students abstract and dazed. The use of network multimedia teaching, teachers can choose a good place for students to listen to the sound, and you can play repeatedly until the color into the emotional design. Such intuitive teaching allows students to have a strong desire to learn, entertaining, improve student learning and quality training content.

The Network Multimedia Teaching Can Increase the Teaching Capacity and Experience. In order to allow students has a scientific understanding of color in clothing color design courses, teachers often use live color ways to stimulate students' visual senses. Such wasted a lot of time, but also by the temporary color light weather a certain color. This eliminates the need for network multimedia teaching session, the teacher can put before class color fine, accurate color presentation in front of the students, saving classroom time, so that teachers can teach more knowledge in the same amount of time, increasing the amount of accumulated knowledge. For example, in the clothing color design course curriculum together hue reconcile traditional teaching can recognize up to 20 colors in one class, but it can at least use the network multimedia teaching awareness hundred colors. This will not only increase the students' experience, and intuitive so that students understand the wonders of color matching, effectively improve the quality of teaching.

\section{The Disadvantages of Network Multimedia Teaching in Clothing Color Design}

Networked multimedia in teaching should follow the "subsidiarity" principle, the use of it in the classroom to be just right, you cannot make students in a passive acceptance of knowledge and information in teaching. In addition, " courseware " is a media network multimedia teaching, the emergence of this medium allows teachers abandon the blackboard in class, students do not need to do notes, and just copy courseware, teachers and students to increase inert. Meanwhile, some teachers in the production of courseware adding too much animation, audio, etc., although seemingly wonderful but did not have much substance, dispersed the students' attention, students passively watch, ignoring the practical exercises is to strengthen knowledge important means ultimately unable to achieve good teaching results. The use of network multimedia teaching is to help teachers inspire students' thinking and description in the process of teaching and learning, not only emphasizes the teaching capacity of the student's ability to accept and ignore. Therefore, teachers in the courseware to be scientifically sound and closely linked to the teaching content, while in the form of expression is again simple, clear and in line with students' cognitive. In order to achieve increased proactive and interest in learning. 


\section{The Advantages of Traditional Teaching in Clothing Color Design}

Traditional teaching method includes lectures, discussions, experiment, presentation method, etc., for the clothing color design courses, presentations law is an essential way of teaching, presentation method is the most intuitive and effective to convey to students the practical expression. For professional courses designed for "inspire" students' thinking is extremely important, intuitive face traditional teaching of students, teachers charisma to the show, and through body language, eye contact with the students emotional communication, helping students to think of mental training, the students watch to the teacher's face is easy to have a positive reaction, followed by teachers to lead thinking, better interact and increase the classroom atmosphere. Traditional teaching teachers blackboard slow, while writing speaking, knowledge of key and difficult encounter mark, there is a process of digestion slow thinking for some students, but also to grasp the teaching content has some control.

\section{The Disadvantages of Traditional Teaching in Clothing Color Design}

Plus chalk blackboard teaching mode, teaching is the color of clothing lack of visual stimulation, too abstract color so that students cannot imagine the spirit of excitement. Traditional teaching teachers can only come through charts, painting demonstration to students cannot be dynamic and static changes in vivid expression, especially as some of the new popular information, post videos cannot be expressed, the students imagined confused and dazed, and then lose interest in learning, teaching effectiveness cannot achieve the desired value. Meanwhile, the traditional teaching slow transmission of information, too much emphasis on teaching the knowledge structure, clothing color design is a large information capacity and rapid changes in curriculum, teaching methods such knowledge often lags, cannot bring new teaching highlights to students.

\section{The Complementary of Network Multimedia and Traditional Teaching in Color Costume Design}

The Network Multimedia is Auxiliary Tool and the Heuristic Teaching Mode is Throughout the Teaching Process. Clothing color design needs colorful pictures and the latest fashion information, multimedia network is the best way to express. For a better understanding of the course content, you can use the network of multimedia images, audio and other auxiliary design teaching content. But in the teaching the heuristic teaching thinking is always as the main teaching methods, inspired students to think step by step, using teaching method and discussion method to stimulate students' enthusiasm and interest. However, we cannot over-reliance on networked multimedia and cannot excessive use the video and animation to rendering teaching content and affect the teaching effectiveness and quality.

Strengthen the Quality of Network Multimedia Courseware. Multimedia courseware is a network media and modern means of education teachers teaching environment does make a change on, for expanding students' knowledge provides a hardware platform, but the support, good courseware production hardware is inseparable from the software is good software. Teachers need to spend time and energy to the process of designing the classroom, teaching and curriculum content and content-related material. Especially clothing color design inspired design covers the contents of the teaching process should good design, conduct two-way exchange of information, to guide students' thinking training, so as to achieve the purpose of teaching.

Combined Traditional Methods with Network Multimedia Teaching and Keep it Throughout the Teaching Process. Costume design, color theory more color concepts and classifications and practices more suited to traditional teaching methods. Explain in detail step by step demonstration by teachers and students followed the teacher's idea of a better understanding of the principles of the use, and enhance memory to achieve the purpose of practice makes perfect. To late design aspects of teaching content, with plenty of color networked multimedia cases, a combination of static dynamic fashion show, stimulate students' aesthetic sense, students' divergent 
thinking and creative thinking, the passive acceptance of evolution as the initiative to obtain.

\section{Conclusions}

In short, how to strengthen the effect of teaching and improve the quality of teaching is a question which worth for every teacher to consider about. And make a reasonable and flexible combination of the network multimedia teaching and traditional teaching is an effective way to improve the quality of teaching.

\section{References}

[1] Caiming Hu, Wang Mian: Science Mosaic, Vo1.6 (2007) No.15, p. 127-129

[2] Junjing Wang, Zhao Yan: Science \& Technology Information, Vo1. 14 (2009) No.6, p. 22-29.

[3] Su Tian: Educational research, Vo1. 8 (2010) No.12, p. 201-226.

[4] Mao L.D: Network Information Science, Vo1. 4 (2003) No.6, p. 143-150.

[5] Yalo D.: Color Technology, Vol. 1 (2011) No.2, p. 3-10. 